\section{Scientific journal}

\section{PHYSICAL AND MATHEMATICAL EDUCATION}

Has been issued since 2013.

Науковий журнал

ФІЗИКО-МАТЕМАТИЧНА ОСВІТА

Видається 32013.
ISSN 2413-158X (online)

ISSN 2413-1571 (print)

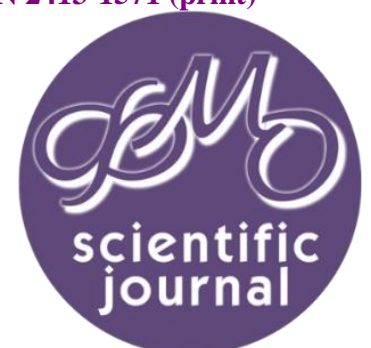

Страх О.П., Лукашова Т.Д. Міждисциплінарні зв'язки при вивченні деяких тем дискретної математики та диреренціальних рівнянь. Фізико-математична освіта. 2021. Випуск 3(29). С. 112-118.

Strakh O., Lukashova T. Interdisciplinary connections in the study of some topics of discrete mathematics and differential equations. Physical and Mathematical Education. 2021. Issue 3(29). P. 112-118.

DOI 10.31110/2413-1571-2021-029-3-017

удк [519.1+517.9](378)

О.П. Страх

Сумський державний педагогічний університет імені А.С. Макаренка, Україна strah_o@ukr.net ORCID: 0000-0002-7680-5716

Т.Д. Лукашова

Сумський державний педагогічний університет імені А.С. Макаренка, Україна tanya.lukashova2015@gmail.com ORCID: 0000-0002-1465-9530

\title{
МІЖДИСЦИПЛІНАРНІ ЗВ'ЯЗКИ ПРИ ВИВЧЕННІ ДЕЯКИХ ТЕМ ДИСКРЕТНОЇ МАТЕМАТИКИ ТА ДИФЕРЕНЦІАЛЬНИХ РІВНЯНЬ
}

АНОТАЦІЯ

Найважливішим завданням підготовки майбутніх фахівців у галузі математики є розширення й поглиблення математичних знань з метою їх комплексного застосування на практиці, в майбутній науковій та професійній діяльності. Одним зі шляхів реалізації такого завдання є використання міждисциплінарних зв'язків, які передбачають перенесення методів дослідження і моделей з однієї наукової дисципліни в іншу.

Формулювання проблеми. у даній статті розглядається можливість реалізації міждисциплінарних зв'язків дискретної математики та диференціальних рівнянь на прикладі вивчення тем "Лінійні рекурентні співвідношення зі сталими коефіцієнтами» та "Лінійні диференціальні рівняння зі сталими коефіцієнтами».

Матеріали і методи. Авторами використовувались наступні методи досліджень: системний аналіз наукової, навчальної та методичної літератури; порівняння та синтез теоретичних положень, розкритих в науковій та навчальній літературі; узагальнення власного педагогічного досвіду та досвіду колег з інших закладів вищої освіти. Окрім того, були використані деякі загально математичні та спеціальні методи теорії диференціальних рівнянь, дискретної математики та різницевого числення.

Результати. Одним зі способів розв'язування лінійних однорідних рекурентних співвідношень зі сталими коефіцієнтами $\epsilon$ складання характеристичного рівняння і запис загального розв'язку вихідного співвідношення залежно від значень знайдених характеристичних коренів. Аналогічний алгоритм використовується й для знаходження загального розв'язку лінійних однорідних диференціальних рівнянь зі сталими коефіцієнтами. У статті встановлено зв'язок між розв'язками рекурентних співвідношень та диференціальних рівнянь, які відповідають одному різницевому рівнянню.

Висновки. Встановлення зв'язків між моделями і методами дослідження, які використовуються при вивченні різних математичних дисциплін, що входять у програму підготовки майбутніх фахівців-математиків, дозволяє срормувати у студентів цілісне уявлення про математичні об'єкти, алгоритми і теорії, і як наслідок, робить їх знання системними і практично більш значущими. Це сприяє інтелектуальному розвитку студентів, формуванню в них системних математичних знань, підвищенню рівня математичної грамотності та інтересу до предмету.

КЛЮчОВІ СлОвА: міждисциплінарні зв'язки, дискретна математика, диференціальні рівняння, рекурентні співвідношення, різницеве числення.

\section{ВСТУП}

Постановка проблеми. У наш час одним із завдань вищої освіти $є$ формування у студентів вміння вирішувати складні завдання із використанням системного підходу. Дієвим засобом реалізації такого завдання $€$ використання міждисциплінарних (або міжпредметних) зв'язків, які передбачають перенесення методів дослідження і моделей з однієї наукової дисципліни в іншу (Батечко\&Титаренко, 2016). Такі зв'язки між різними дисциплінами професійної підготовки студентів у зВО є конкретним виразом інтеграційних процесів, що відбуваються сьогодні в науці та суспільстві. Вони 
сприяють розв'язанню існуючих суперечностей між розрізненими знаннями студентів з різних дисциплін та необхідністю їх подальшого синтезу та комплексного застосування на практиці, в майбутній науковій та професійній діяльності. За допомогою міждисциплінарних зв'язків не лише вирішуються завдання навчання, розвитку і виховання студентів, але й закладається фундамент для комплексного бачення й оволодіння прийомами вирішення складних проблем реальної дійсності (Козлов\& Томашевська \& Кузнєцов, 2018).

Слід зазначити, що встановлення міждисциплінарних зв'язків $€$ досить складною задачею навіть у межах однієї спеціальності, оскільки передбачає не лише перегляд змісту програм відповідних навчальних дисциплін, а й узгодження методики роботи різних викладачів. При цьому необхідність встановлення зв'язків між різними математичними дисциплінами у вищій школі диктується як дидактичними цілями навчання, так і необхідністю підготувати студентів до професійної та наукової діяльності, де одним з умінь є здатність вирішувати завдання комплексно.

У даній статті розглядається можливість реалізації міждисциплінарних зв'язків дискретної математики та теорії диференціальних рівнянь, що входять у цикл професійної підготовки майбутніх вчителів математики.

Аналіз актуальних досліджень. Проблемі реалізації міждисциплінарних зв'язків у вищій школі присвячена ціла низка як вітчизняних, так і закордонних робіт (Ананченко\&Вороніна\&Скороходова, 2020; Бевз, 2003; Васьківська, 2017; Волобуєва, 2015; Козлов\& Томашевська\&Кузнєцов, 2018; Колот, 2014; Коржова 2017; Філіпенко, 2017; Шкура, 2020; Styron Ronald, 2013), що підтверджує актуальність та значущість означеної проблеми в системі освіти.

Незважаючи на значну кількість подібних досліджень, проблема реалізації міжпредметних зв'язків між різними математичними дисциплінами фактично залишається не вивченою, за виключенням перенесення окремих методів і моделей з математичного аналізу у методи обчислень, з лінійної алгебри у математичне програмування, з теорієї ймовірностей у математичну статистику. В той же час такі зв'язки можна встановити між змістом окремих тем цілого ряду інших, на перший погляд, далеких одна від одної дисциплін, зокрема, між дискретною математикою та теорією диференціальних рівнянь.

Дискретна математика (у західних джерелах дискретний аналіз) - це розділ математики, пов'язаний із дослідженнями різних об'єктів та структур, заданих на скінченних множинах. Специфіка дискретної математики полягає у відмові від основних понять класичної («неперервної») математики - границі та неперервності. Тому для задач дискретної математики звичайні засоби класичного аналізу є допоміжними. Але дискретна та класична («неперервна») математики взаємно доповнюють одна одну, а в окремих випадках мають схожий апарат дослідження, що робить можливим побудову зв'язків між відповідними теоріями.

Традиційно до дискретної математики відносять різницеве числення, що $\epsilon$ дискретним аналогом диференціального та інтегрального числення, і яке відіграє важливу роль в теорії числових послідовностей, комбінаторному аналізі та теорії графів. Одним зі способів розв'язування окремих видів різницевих рівнянь $€$ складання характеристичного рівняння і запис загального розв'язку вихідного рівняння залежно від значень знайдених характеристичних коренів. Аналогічний алгоритм використовується й для знаходження загального розв'язку лінійних однорідних рекурентних співвідношень та лінійних однорідних диференціальних рівнянь зі сталими коефіцієнтами. Різною $є$ лише форма запису відповіді, що пояснюється різними множинами визначення шуканих функцій (у першому випадку ця множина є дискретною, у другому - неперервною). Таким чином, виникає задача знаходження зв'язків між характеристичними рівняннями і коренями цих рівнянь в дискретному і неперервному випадках.

Метою статті $\epsilon$ встановлення міждисциплінарних зв'язків дискретної математики та диференціальних рівнянь на прикладі вивчення тем «Лінійні рекурентні співвідношення зі сталими коефіцієнтами» та «Лінійні диференціальні рівняння зі сталими коефіцієнтами».

\section{МЕТОДИ ДОСЛІДЖЕННЯ}

У статті використано наступні теоретичні та емпіричні методи досліджень: системний аналіз наукової, навчальної та методичної літератури; порівняння та синтез теоретичних положень, розкритих в науковій та навчальній літературі; узагальнення власного педагогічного досвіду та досвіду колег з інших закладів вищої освіти. Окрім того, були використані деякі загально математичні та спеціальні методи теорії диференціальних рівнянь, дискретної математики та різницевого числення.

\section{РЕЗУЛЬТАТИ ДОСЛІДЖЕННЯ}

Тема «Рекурентні співвідношення» $€$ самостійною темою дискретної математики і не потребує знань інших тем цієї дисципліни (окрім, можливо, теми «Твірні функції», де розглядається один з методів розв'язування рекурентних співвідношень із застосуванням генератрис). Виявляється, що для відшукання розв'язків лінійного рекурентного співвідношення (рівняння) зі сталими коефіцієнтами може бути використаний той же алгоритм, що і для знаходження розв'язків лінійного диференціального рівняння зі сталими коефіцієнтами.

Розглянемо лінійне однорідне рекурентне співвідношення степеня $k$ зі сталими коефіцієнтами:

$$
\alpha_{k} a_{n+k}+\alpha_{k-1} a_{n+k-1}+\ldots+\alpha_{1} a_{n+1}+\alpha_{0} a_{n}=0,
$$

де $\left(a_{n}\right)_{n \in \mathbb{N}}$ - деяка послідовність, а $\alpha_{i} \in \mathbb{R}$ - задані коефіцієнти $(i=\overline{1, k})$. Для того, щоб розв'язати рекурентне співвідношення (1), необхідно скласти і розв'язати відповідне характеристичне рівняння:

що має ті ж коефіцієнти (Гельфонд, 1959).

$$
\alpha_{k} \lambda^{k}+\alpha_{k-1} \lambda^{k-1}+\ldots+\alpha_{1} \lambda+\alpha_{0}=0
$$

Зрозуміло, що розв'язками цілого алгебраїчного рівняння (2) з дійсними коефіцієнтами можуть бути як різні так і однакові дійсні чи комплексні числа. Нехай $\lambda_{1}, \lambda_{2}, \ldots, \lambda_{s}$ - корені характеристичного рівняння (2) з відповідною кратністю $k_{1}, k_{2}, \ldots, k_{s}$. Тоді загальний розв'язок рівняння (1) матиме вигляд: 


$$
\begin{gathered}
a_{n}=\lambda_{1}^{n}\left(C_{1}^{(1)}+C_{1}^{(2)} n+\ldots+C_{1}^{\left(k_{1}\right)} n^{k_{1}-1}\right)+\lambda_{2}^{n}\left(C_{2}^{(1)}+C_{2}^{(2)} n+\ldots+C_{2}^{\left(k_{2}\right)} n^{k_{2}-1}\right)+\ldots+ \\
+\lambda_{s}^{n}\left(C_{s}^{(1)}+C_{s}^{(2)} n+\ldots+C_{s}^{\left(k_{s}\right)} n^{k_{s}-1}\right),
\end{gathered}
$$

де $C_{i}^{(j)}$ - довільні дійсні (або комплексні) сталі.

Якщо проаналізувати структуру розв'язку (3), то всі доданки, що до нього входять $є$ лінійно незалежними функціями.

Розглянемо тепер лінійне однорідне диференціальне рівняння порядку $k$ зі сталими коефіцієнтами

$$
\alpha_{k} y^{(k)}+\alpha_{k-1} y^{(k-1)}+\ldots+\alpha_{1} y^{\prime}+\alpha_{0} y=0,
$$

де $y=y(x)$ - шукана функція, а $\alpha_{i} \in \mathbb{R}$ - задані коефіцієнти $(i=\overline{1, k})$.

Як відомо (Шкіль\&Лейфура\&Самусенко, 2003), розв'язок такого рівняння має вигляд

$$
\begin{gathered}
y(x)=e^{\lambda_{1} x}\left(C_{1}^{(1)}+C_{1}^{(2)} x+\ldots+C_{1}^{\left(k_{1}\right)} x^{k_{1}-1}\right)+e^{\lambda_{2} x}\left(C_{2}^{(1)}+C_{2}^{(2)} x+\ldots+C_{2}^{\left(k_{2}\right)} x^{k_{2}-1}\right)+\ldots+ \\
+e^{\lambda_{s} x}\left(C_{s}^{(1)}+C_{s}^{(2)} x+\ldots+C_{s}^{\left(k_{s}\right)} x^{k_{s}-1}\right),
\end{gathered}
$$

де $\lambda_{1}, \lambda_{2}, \ldots, \lambda_{s}$ - корені характеристичного рівняння (2), а $k_{1}, k_{2}, \ldots, k_{s}$ - їх кратності відповідно.

Формули (3) та (5) і методи знаходження розв'язків рекурентного співвідношення (1) та диференціального рівняння (4) мають багато спільного. Відтак, виникає природне питання: чи не можна записати розв'язки (3) і (5) рекурентного співвідношення (2) і диференціального рівняння (4) відповідно якоюсь загальною формулою? Відповідь на це питання позитивна, проте потребує застосування поняття так званого різницевого рівняння.

Різницеві рівняння $€$ аналогом рекурентних співвідношень в теорії диференціальних рівнянь. Їх можна отримати з відповідного лінійного диференціального рівняння шляхом заміни похідних функції $y(x)$

$$
y^{\prime}(x), y^{\prime \prime}(x), \ldots y^{(k-1)}(x), y^{(k)}(x)
$$

на значення різницевого оператора $\Delta y(x)($ Андерсон, 2004), а саме:

$$
\begin{gathered}
\Delta y(x):=y(x+1)-y(x), \\
\Delta^{2} y(x):=\Delta(\Delta y(x))=\Delta(y(x+1)-y(x))=y(x+2)-2 y(x+1)+y(x), \ldots, \\
\Delta^{(k)} y(x):=\sum_{i=0}^{k}(-1)^{i} C_{k}^{i} y(x+k-i)
\end{gathered}
$$

відповідного порядку (тут коефіцієнти $C_{k}^{i}$ - це добре відомі у кожному з розділів математики біноміальні коефіцієнти, які визначаються як комбінації без повторень з $k$ елементів по $i)$.

Таким чином, різницеве рівняння, яке відповідає диференціальному рівнянню (4), матиме вигляд:

$\alpha_{k} \sum_{i=0}^{k}(-1)^{i} C_{k}^{i} y(x+k-i)+\alpha_{k-1} \sum_{i=0}^{k-1}(-1)^{i} C_{k-1}^{i} y(x+k-1-i)+\ldots+\alpha_{1}(y(x+1)-y(x))+\alpha_{0} y=0$,

або

$$
\begin{gathered}
\alpha_{k}(-1)^{0} C_{k}^{0} y(x+k)+\left(\alpha_{k}(-1)^{1} C_{k}^{1}+\alpha_{k-1}(-1)^{0} C_{k-1}^{0}\right) y(x+k-1)+\ldots+ \\
+\sum_{i=0}^{k-1} \alpha_{i+1}(-1)^{i} C_{i+1}^{i} y(x+1)+\sum_{i=0}^{k} \alpha_{i}(-1)^{i} C_{i}^{i} y(x)=0 .
\end{gathered}
$$

При цьому, якщо аргумент $x$ шуканої функції $y(x) \in$ натуральним числом, то рівність (6) $є$ записом деякого лінійного рекурентного співвідношення.

Покажемо, що розв'язки характеристичного рівняння (2) рекурентного співвідношення (1) безпосередньо пов'язані з розв'язками характеристичного рівняння для різницевого рівняння (6), тобто розв'язками рівняння:

$$
\begin{aligned}
& \alpha_{k}(-1)^{0} C_{k}^{0} \lambda^{k}+\left(\alpha_{k}(-1)^{1} C_{k}^{1}+\alpha_{k-1}(-1)^{0} C_{k-1}^{0}\right) \lambda^{k-1}+\ldots+ \\
& \quad+\sum_{i=0}^{k-1} \alpha_{i+1}(-1)^{i} C_{i+1}^{i} \lambda+\sum_{i=0}^{k} \alpha_{i}(-1)^{i} C_{i}^{i}=0 .
\end{aligned}
$$

Покажемо, якщо деяке число $\tilde{\lambda} \in$ розв'язком рівняння (7), то число $(\tilde{\lambda}-1) \in$ розв'язком рівняння (2). Дійсно, скориставшись розкладом бінома Ньютона, маємо:

$$
\begin{gathered}
\alpha_{k}(\tilde{\lambda}-1)^{k}+\alpha_{k-1}(\tilde{\lambda}-1)^{k-1}+\ldots+\alpha_{1}(\tilde{\lambda}-1)+\alpha_{0}=\alpha_{k} \sum_{i=0}^{k}(-1)^{i} C_{k}^{i} \tilde{\lambda}^{k-i}+ \\
+\alpha_{k-1} \sum_{i=0}^{k-1}(-1)^{i} C_{k-1}^{i} \tilde{\lambda}^{k-1-i}+\ldots+\alpha_{2} \sum_{i=0}^{2}(-1)^{i} C_{2}^{i} \tilde{\lambda}^{2-i}+\alpha_{1}(\tilde{\lambda}-1)+\alpha_{0}= \\
=\alpha_{k}(-1)^{0} C_{k}^{0} \tilde{\lambda}^{k}+\left(\alpha_{k}(-1)^{1} C_{k}^{1}+\alpha_{k-1}(-1)^{0} C_{k-1}^{0}\right) \tilde{\lambda}^{k-1}+\ldots+ \\
+\sum_{i=0}^{k-2} \alpha_{i+2}(-1)^{i} C_{i+2}^{i} \tilde{\lambda}^{2}+\sum_{i=0}^{k-1} \alpha_{i+1}(-1)^{i} C_{i+1}^{i} \tilde{\lambda}+\sum_{i=0}^{k} \alpha_{i}(-1)^{i} C_{i}^{i}
\end{gathered}
$$

тобто отримуємо ліву частину рівняння (7).

Отже, знаючи розв'язки рівняння (2), можна легко отримати розв'язки рівняння (6), яке у свою чергу можна записати через введення до розгляду різницевого оператора $\Delta$, і навпаки.

Маючи отриманий вище результат, вид розв'язку (5) диференціального рівняння (4) можна пов'язати з загальним виглядом розв'язку (7) рекурентного співвідношення (6) за допомогою функції:

$$
\xi_{h}(z)=\left\{\begin{array}{l}
z, \text { якщо } h=0, \\
\frac{1}{h} \operatorname{Ln}(1+z h), \text { якщо } h>0,
\end{array}\right.
$$

де $\omega=\operatorname{Ln}(t)$ - натуральний логарифм комплексного числа $t$, який визначається з рівності $e^{\omega}=t$.

Якщо за $h$ позначити відстань між елементами області визначення $M$ шуканої функції $y(x)$, то для представлення загального розв'язку і диференціального рівняння (4) і рекурентного співвідношення (6) можна визначити функцію: 


$$
\xi(z, x)=\left\{\begin{array}{l}
z, \text { якщо } \inf \{s \in M, s>x\}=x, \\
\operatorname{Ln}(1+z), \text { якщо } \inf \{s \in M, s>x\}=x+1 .
\end{array}\right.
$$

3 формули (9) для $x \in \mathbb{N}$ одержимо $e^{x \xi(\lambda, x)}=e^{x \operatorname{Ln}(1+\lambda)}=(1+\lambda)^{x}$ і тому спільний вигляд розв'язків рівнянь (4) $\mathrm{i}$ (6) буде наступним:

$$
\begin{gathered}
y(x)=e^{x \xi\left(\lambda_{1}, x\right)}\left(C_{1}^{(1)}+C_{1}^{(2)} x+\ldots+C_{1}^{\left(k_{1}\right)} x^{k_{1}-1}\right)+e^{x \xi\left(\lambda_{2}, x\right)}\left(C_{2}^{(1)}+C_{2}^{(2)} x+\ldots+C_{2}^{\left(k_{2}\right)} x^{k_{2}-1}\right)+\ldots+ \\
+e^{x \xi\left(\lambda_{s}, x\right)}\left(C_{s}^{(1)}+C_{s}^{(2)} x+\ldots+C_{s}^{\left(k_{s}\right)} x^{k_{s}-1}\right),
\end{gathered}
$$

де $\lambda_{1}, \lambda_{2}, \ldots, \lambda_{s}$ знову $є$ коренями характеристичного рівняння (2), а $k_{1}, k_{2}, \ldots, k_{s}$ - їх кратності відповідно.

Проілюструємо отриманий вище результат на прикладі.

Приклад 1. За даним диференціальним рівнянням

$$
y^{(4)}+y^{\prime \prime \prime}-15 y^{\prime \prime}+23 y^{\prime}-10 y=0
$$

побудувати відповідне рекурентне співвідношення та отримати розв'язки кожного з них.

\section{Розв'язання}

Для заданого рівняння (11) запишемо відповідне характеристичне рівняння та розв'яжемо його:

$$
\lambda^{4}+\lambda^{3}-15 \lambda^{2}+23 \lambda-10=0 .
$$

Скориставшись схемою Горнера, знайдемо раціональні корені рівняння (12):

\begin{tabular}{c|c|c|c|c|c|c} 
& 1 & 1 & -15 & 23 & -10 & \\
\hline$\lambda=-1$ & 1 & 0 & -15 & 38 & $-48 \neq 0$ & не $\epsilon$ коренем \\
\hline$\lambda=1$ & 1 & 2 & -13 & 10 & 0 & $\epsilon$ коренем \\
\hline$\lambda=1$ & 1 & 3 & -10 & 0 & \multicolumn{4}{c}{$\epsilon$ коренем } \\
\hline
\end{tabular}

тобто $\lambda=1 €$ двократним коренем рівняння (12). Інші ж 2 корені знайдемо з отриманого за схемою Горнера квадратного рівняння $\lambda^{2}+3 \lambda-10=0$. За теоремою Вієта маємо $\lambda_{3}=-5$ і $\lambda_{4}=2$.

За формулою (5) загальний розв'язок даного диференціального рівняння (11) має вигляд:

$$
y(x)=e^{x}\left(C_{1}^{(1)}+C_{1}^{(2)} x\right)+C_{2} e^{-5 x}+C_{3} e^{2 x} .
$$

Запишемо тепер різницеве рівняння, увівши замість похідних відповідний порядок різницевого оператора:

$$
\Delta^{4} y(x)+\Delta^{3} y(x)-15 \Delta^{2} y(x)+23 \Delta y(x)-10 y(x)=0 .
$$

Скориставшись виразом у лівій частині рівняння (6), одержимо наступне рекурентне співвідношення

$$
\begin{gathered}
y(x+4)+\left(-C_{4}^{1}+C_{3}^{0}\right) y(x+3)+\left(C_{4}^{2}-C_{3}^{1}-15 C_{2}^{0}\right) y(x+2)+\left(-C_{4}^{3}+C_{3}^{2}+15 C_{2}^{1}+23 C_{1}^{0}\right) y(x+1)+ \\
+(1-1-15-23-10) y(x)=0,
\end{gathered}
$$

або

$$
y(x+4)-3 y(x+3)-12 y(x+2)+52 y(x+1)-48 y(x)=0 .
$$

Його характеристичне рівняння має вигляд:

$$
\lambda^{4}-3 \lambda^{3}-12 \lambda^{2}+52 \lambda-48=0,
$$

а коренями $€$ числа $\tilde{\lambda}_{1,2}=2, \tilde{\lambda}_{3}=-4, \tilde{\lambda}_{4}=3$. У відповідності з (3), загальний розв'язок рекурентного співвідношення (13) $€$ наступним:

$$
y(x)=2^{x}\left(C_{1}^{(1)}+C_{1}^{(2)} x\right)+C_{2}(-4)^{x}+C_{3} 3^{x} .
$$

3 іншого боку, за формулою (10) розв'язок рекурентного співвідношення (13) можна знайти, виходячи з коренів характеристичного рівняння (12) вихідного диференціального рівняння (11):

$$
y(x)=(1+1)^{x}\left(C_{1}^{(1)}+C_{1}^{(2)} x\right)+C_{2}(-5+1)^{x}+C_{3}(2+1)^{x}=2^{x}\left(C_{1}^{(1)}+C_{1}^{(2)} x\right)+C_{2}(-4)^{x}+C_{3} 3^{x} .
$$

Як бачимо, розв'язок отримано правильно.

Наведений вище підхід демонструє тісний зв'язок між коренями характеристичних рівнянь лінійних однорідних рекурентних співвідношень та лінійних однорідних диференціальних рівнянь зі сталими коефіцієнтами, що мають досить схожі алгоритми розв'язування і вивчаються в курсах дискретної математики та диференціальних рівнянь.

\section{ОБГОВОРЕННЯ}

Слід зазначити, що на сьогоднішній день існує теорія, яка дозволяє розглядати об'єкти у неперервно-дискретному за часом режимі. Це так звана теорія динамічних рівнянь на часовій шкалі. Вона була запропонована порівняно недавно (у 1988 році) німецьким математиком Стефаном Хільгером та ґрунтується на понятті часової шкали як довільної непорожньої та замкненої (з погляду теорії множин) підмножини множини дійсних чисел. Ця теорія детально описана в роботі (Bohner\&Peterson, 2001). Тоді ж вибір функції $\xi_{h}(z)$, поданої у (8), не $\epsilon$ випадковим.

Функція $\xi_{h}(z)$ визначає деяке циліндричне перетворення комплексної площини та визначає так звану експоненціальну функцію на довільні часовій шкалі:

$$
e_{p(t)}\left(t, t_{0}\right)=e^{\int_{t_{0}}^{t} \xi_{\mu(\tau)}(p(\tau)) \Delta \tau},
$$

де $\mu(t)$ - функція відстані між елементами часової шкали (називають також зернистістю часової шкали), а $\Delta \tau-$ $\Delta$-диференціал змінної, який визначає звичайний диференціал $d \tau$, коли часова шкала $є$ неперервним відрізком, або дорівнює $h$, коли часова шкала $€$ дискретним відрізком із кроком $h$ (Bohner\&Peterson, 2001). Диференціал $\Delta$ також пов'язаний зі знаходженням $\Delta$-похідної функції $y^{\Delta}(x)$, яка є звичайною похідною $y^{\prime}(x)$ у випадку дійсного відрізка, або визначає різницевий оператор $\Delta y(x)=y(x+1)-y(x)$ у випадку дискретного відрізка на множині цілих чисел.

Зазначена експоненціальна функція (14) узагальнює поняття розв'язку нелінійного однорідного диференціального чи різницевого рівняння першого порядку. Так, розглядаючи так зване динамічне рівняння першого порядку на часовій шкалі 
отримуємо розв'язок виду:

$$
y^{\Delta}(x)=p(x) y(x)
$$

$$
y(x)=C e_{p(t)}\left(t, t_{0}\right) .
$$

Тоді розв'язок відповідного диференціального рівняння $y^{\prime}(x)=p(x) y(x)$ буде мати вигляд

$$
y(x)=C e^{\int p(x) d x}
$$

тоді як розв'язком відповідного різницевого рівняння $\Delta y(x)=p(x) y(x)$ буде:

$$
y(x)=C e^{\sum_{t=x_{0}}^{x} \operatorname{Ln}(1+p(t))}=C e^{L n \prod_{t=x_{0}}^{x}(1+p(t))}=C \prod_{t=x_{0}}^{x}(1+p(t)) .
$$

Розглянемо приклад застосування зазначеної теорії до розв'язування нелінійних рекурентних співвідношень.

Приклад 2. Розв'язати рекурентне співвідношення $a_{n+1}-(n+1) a_{n}=0$.

\section{Розв'язання}

Запишемо спочатку задане рекурентне співвідношення у вигляді різницевого рівняння:

або

$$
a_{n+1}-a_{n}-n a_{n}=\Delta a(n)-n a(n)=0,
$$

тоді, скориставшись виглядом розв'язку (15), одержимо:

$$
a(n)=C \prod_{k=1}^{n}(1+k)=C n ! \text {. }
$$

Отже, розв'язками заданого рекурентного співвідношення $є$ послідовності виду $a_{n}=C n$ !.

\section{ВИСНОВКИ ТА ПЕРСПЕКТИВИ ПОДАЛЬШОГО ДОСЛІДЖЕННЯ}

Підводячи підсумки, зазначимо, що встановлення зв'язків між різними математичними дисциплінами допомагає сформувати в студентів цілісне уявлення про математичні об'єкти, алгоритми і теорії, і як наслідок, робить знання системними і практично більш значущими. Виявлення таких зв'язків сприяє інтелектуальному розвитку студентів, формуванню в них системних математичних знань, підвищенню рівня математичної грамотності та інтересу до навчання.

\section{Список використаних джерел}

1. Ананченко Ю.М., Вороніна Н.К., Скороходова Л.І. Бінарне заняття як форма реалізації міждисциплінарних зв'язків у процесі підготовки студентів в умовах закладу фахової передвищої освіти: з досвіду машинобудівного коледжу Сумського державного університету. Фізико-математична освіта, 2020. Випуск 3(25). Частина 1. С. 19-24.

2. Андерсон Дж. А. Дискретная математика и комбинаторика. М.: Изд. дом «Вильямс», 2004. 960 с.

3. Батечко Н., Титаренко І. Розвиток магістратури в Україні на засадах міждисциплінарності. Неперервна професійна освіта: теорія і практика. Серія: педагогічні науки, 2016. №3. С. 17-22.

4. Бевз В. Міжпредметні зв'язки як необхідний елемент предметної системи навчання. Математика в школі, 2003 . №6. C. 6-11.

5. Васьківська Г.О. Дидактичні аспекти реалізації міждисциплінарних зв'язків у процесі фахової підготовки студентів вищих педагогічних навчальних закладів. Тенденції розвитку сучасної освіти, 2017. №3-4. С. 137-149.

6. Волобуєва О.Ф. Міждисциплінарні (міжпредметні) зв'язки під час підготовки майбутнього фахівця: психологічний аспект. Збірник наукових праць Національної академії Державної прикордонної служби України. Серія: Психологічні науки, 2015. № 1. С. 26-42.

7. Гельфонд А .О. Исчисление конечных разностей. М.: Гос. изд-во физ.-мат. лит-ры., 1959.400 с.

8. Кобильник Т.П. Використання міжпредметних зв'язків при навчанні математичної інформатики у педагогічному університеті. Науковий часопис НПУ імені М.П. Драгоманова. Серія 2. Комп'ютерно-орієнтовані системи навчання, 2010. Випуск 8(15). С.143-148.

9. Козлов В.В., Томашевська Т.В., Кузнєцов М.І., Використання міждисциплінарних зв'язків при підготовці майбутніх фахівців зі статистики. Статистика України, 2018. № 1. С. 52-60.

10. Колот А.М. Міждисциплінарний підхід як домінанта розвитку економічної науки та освітньої діяльності. Социальная экономика, 2014. № 1-2. С. 76-83.

11. Коржова О.В. Теоретичні аспекти міжпредметних зв'язків математичних дисциплін з дисциплінами циклу професійної підготовки майбутніх фахівців із організації інформаційної безпеки. Фізико-математична освіта, 2017. Випуск 2(12). С. 89-93.

12. Філіпенко А. С. Міждисциплінарна методологія: базові принципи. «Міждисциплінарні дискусї̈, 2017. URL: http://www.iir.edu.ua/uploads/files/tezi\%20ceminar\%20synthesis\%205\%2012\% 202017\%20final\%20(1).pdf.

13. Шкіль М.І., Лейфура В.М., Самусенко Л.М. Диференціальні рівняння: навчальний посібник для студентів математичних спеціальностей вищих навч. закл. К.: Техніка, 2003. 386 с.

14. Шкура І. Зарубіжний досвід упровадження міждисциплінарних освітніх програм та можливості його застосування в Україні. Наукові записки БДПУ. Серія: Педагогічні науки, 2020. Випуск 2. С. 114-127.

15. Bohner M., Peterson A. Dynamic equations on time scales. An introduction with applications. Birkhäuser Boston Inc., Boston, MA, 2001. $360 \mathrm{p}$

16. Styron Ronald A., Jr. (2013). Interdisciplinary Education: A Reflection of the Real World. Systemics, cybernetics and informatics, 2013. №9(11). P. 47-52.

\section{References}

1. Ananchenko, Yu., Voronina, N. \& Skorokhodova, L. (2020). Binarne zaniattia yak forma realizatsii mizhdystsyplinarnykh zviazkiv u protsesi pidhotovky studentiv v umovakh zakladu fakhovoi peredvyshchoi osvity: z dosvidu mashynobudivnoho koledzhu Sumskoho derzhavnoho universytetu [Binary lesson as a form of implementation of interdisciplinary relations in the 
training of students in the conditions of the institution of professional preliminary education: from the experience of mechanical engineering college]. Fizyko-matematychna osvita - Physical and Mathematical Education, 3(25), Part 1, 19-24 [in Ukrainian].

2. Anderson, J. A. (2004) Discrete Mathematics with Combinatorics [Diskretnaia matematika y kombinatorika]. Moskow: Ed. house "Williams". [in Russian]

3. Batechko, N. \& Tytarenko, I. (2016). Rozvytok reyestratsiyi v Ukrayini na zasadakh mizhdystsyplinarnosti [Development of registration in Ukraine on the basis of interdisciplinarity], Neperevna profesiyna osvita: teoriya i praktyka (Seriya: pedahohichni nauky) - Continuing professional education: theory and practice. Series: pedagogical sciences, 3, 17-22 [in Ukrainian].

4. Bevz, V. (2003) Interdisciplinary links as a necessary element of the subject system of education [Mizhpredmetni zviazky yak neobkhidnyi element predmetnoi systemy navchannia. [terdisciplinary links as a necessary element of the subject system of education]. Matematyka v shkoli - Mathematics at school, 6, 6-11 [in Ukraine].

5. Vas'kivs'ka, H. (2017). Dydaktychni aspekty realizatsiyi mizhdystsyplinarnykh zv"yazkiv u protsesi fakhovoyi pidhotovky studentiv vyshchykh pedahohichnykh navchal'nykh zakladiv [Didactic aspects of realization of interdisciplinary connections in the process of professional training of students of higher pedagogical educational establishments], Tendentsiyi rozvytku suchasnoyi osvity - Trends in the development of modern education, 3-4, 137-149 [in Ukrainian].

6. Volobuyeva, O. (2015). Mizhdystsyplinarni (mizhpredmetni) zv`yazky pid chas pidhotovky maybutn'oho fakhivtsya: psykholohichnyy aspekt [Interdisciplinary (interdisciplinary) connections during the preparation of the future specialist: psychological aspect], Zbirnyk naukovykh prats' Natsional'noyi akademiyi Derzhavnoyi prykordonnoyi sluzhby Ukrayiny. Seriya: Psykholohichni nauky - Proceedings of the National Academy of State Border Service of Ukraine. Series: Psychological Sciences, 1, 26-42 [in Ukrainian].

7. Gelfond, A.O. (1959). Ischislenie konechnyh raznostej [Finite Difference Calculus]. M.: State Publishing House of Phys.-Math. Literature [in Russian].

8. Kobylnyk, T.P. (2010) Vykorystannia mizhpredmetnykh zviazkiv pry navchanni matematychnoi informatyky u pedahohichnomu universytet [The use of interdisciplinary links in the teaching of mathematical computer science at the Pedagogical University]. Naukovyi chasopys NPU imeni M.P. Drahomanova. Seriia 2. Kompiuterno-oriientovani systemy navchannia - Scientific journal of NPU named after M.P. Dragomanov. Series 2. Computer-based learning systems, 8 (15), 143-148 [in Ukrainian].

9. Kozlov, V.V., Tomashevska, T.V. \& Kuznietsov, M.I. (2018) Vykorystannia mizhdystsyplinarnykh zviazkiv pry pidhotovtsi maibutnikh fakhivtsiv zi statystyky [Use of Interdisciplinary Links in the Training of Future Specialists in Statistics]. Statystyka Ukrainy - Statistics of Ukraine, 1, 52-60 [in Ukrainian].

10. Kolot, A.M. (2014). Mizhdystsyplinarnyi pidkhid yak dominanta rozvytku ekonomichnoi nauky ta osvitnoi diialnosti [Interdisciplinary approach as a dominant development of economic science and educational activities]. Sotsialna ekonomika - Social economy, № 1-2, 76-83 [in Ukrainian].

11. Korzhova, O.V. (2017). Teoretychni aspekty mizhpredmetnykh zviazkiv matematychnykh dystsyplin z dystsyplinamy tsyklu profesiinoi pidhotovky maibutnikh fakhivtsiv iz orhanizatsii informatsiinoi bezpeky [Theoretical Aspects Of Interdisciplinary Communications Between Mathematical Disciplines And Disciplines Of Professional Training Of Future Specialists In Organization Of Information Security]. Fizyko-matematychna osvita - Physical and Mathematical Education, 2(12), 89 - 93 [in Ukrainian].

12. Filipenko A. (2017). Mizhdystsyplinarna metodolohiya: bazovi pryntsypy [Interdisciplinary methodology: basic principles], Mizhdystsyplinarni dyskusiyi, Retrieved from: http://www.iir.edu.ua/uploads/files/tezi\%20ceminar \%20synthesis\%205\%2012\% 202017\%20final\%20(1).pdf [in Ukrainian].

13. Shkil, M.I., Leifura, V.M. \& Samusenko, L.M. (2003). Dyferentsialni rivniannia: navchalnyi posibnyk dlia studentiv matematychnykh spetsialnostei vyshchykh navch. zakl. [Differential equations: a textbook for students of mathematical specialties of higher educational instit.]. Kyiv: Tekhnolohiia. [in Ukrainian].

14. Shkura, I.S. (2020). Zarubizhnyi dosvid uprovadzhennia mizhdystsyplinarnykh osvitnikh prohram ta mozhlyvosti yoho zastosuvannia v Ukraini [Foreign experience in implementing interdisciplinary educational programs and opportunities for its application in Ukraine]. Naukovi zapysky BDPU. Seriia: Pedahohichni nauky - Scientific notes of BSPU. Series: Pedagogical sciences, 2, 114-127 [in Ukrainian].

15. Bohner, M. \& Peterson, A. (2001). Dynamic equations on time scales. An introduction with applica- tions. Birkhäuser Boston Inc., Boston, MA.

16. Styron Ronald A., Jr. (2013). Interdisciplinary Education: A Reflection of the Real World. Systemics, cybernetics and informatics, 9(11), 47-52.

\section{INTERDISCIPLINARY CONNECTIONS IN THE STUDY OF SOME TOPICS OF DISCRETE MATHEMATICS AND DIFFERENTIAL EQUATIONS \\ O. P. Strakh, T D. Lukashova \\ Makarenko Sumy State Pedagogical University, Ukraine}

Abstract. One of the important tasks in the training of future specialists in the branch of mathematics is the expansion and deepening of mathematical knowledge in order to apply them comprehensively in practice, in future scientific and professional activities. One way to implement this task is to use interdisciplinary connections that involve the transfer of research methods and research models from one scientific discipline to another.

Formulation of the problem. This article considers the possibility of implementing interdisciplinary connections of discrete mathematics with differential equations on the example of studying the topics "Linear recurrence relations with constant coefficients" and "Linear differential equations with constant coefficients». 
Materials and methods. The authors used the following research methods: systematic analysis of scientific, educational and methodological literature; comparison and synthesis of theoretical positions disclosed in scientific and educational literature; generalization of own pedagogical experience and experience of colleagues from other institutions of higher education. In addition, some general mathematical and special methods of the theory of differential equations, discrete mathematics and difference calculus were used.

Results. One of the ways to solve linear homogeneous recurrence relations with constant coefficients is to compile a characteristic equation and write the general solution of a given relation depending on the values of the found characteristic roots. A similar algorithm is used to find the general solution of linear homogeneous differential equations with constant coefficients. The article establishes a connection between the solutions of recurrence relations and differential equations, the characteristic equation of which has the same form.

Conclusions. Establishing connections between models and research methods used in the study of various mathematical disciplines included in the training program for future mathematicians, allows students to form a holistic view of mathematical objects, algorithms and theories, and as a consequence, makes their knowledge is systematic and practically more meaningful. This contributes to the intellectual development of students, the formation of their systematic mathematical knowledge; increase the level of mathematical literacy and interest in studying the discipline.

Keywords: interdisciplinary connections, discrete mathematics, differential equations, recurrence relations, difference calculus.

\section{(c) ) EY-NC-SA}

This work is licensed under Creative Commons Attribution-NonCommercial-ShareAlike 4.0 International License. 